\title{
Research on Regional Differences of Perception of Safety of Tourists - Taking Potential Tourists as an Example
}

\author{
Ding Guijin ${ }^{1 \mathrm{a}}$, Wu Jinfeng ${ }^{1 b^{*}}$ \\ ${ }^{1}$ School of Geography and Tourism, Shaanxi Normal University, Xi'an, China
}

\begin{abstract}
Choosing Xinjiang as a potential tourist destination and the residents from Beijing, Shanghai, Guangzhou and Chengdu as potential tourists, the paper herein analyzes the dimensions of tourists' perception of safety to Xinjiang as well as the differences among them who come from different cities. What we found is as follows: (1) Tourists' perception of safety to Xinjiang includes five dimensions, such as elements of tourist activities, tourism services, social safety, natural disasters, and cultural conflict. (2) There are significant differences in five dimensions of perception of safety in Xinjiang among tourists from different regions. (3) There are differences in the perception of safety to Xinjiang among tourists from different regions while they share something in common in the four dimensions, such as elements of tourist activities, tourism services, social safety and cultural conflicts.
\end{abstract}

\section{Introduction}

Tourism safety is a matter of the utmost importance in the development of tourism industry and it's also the guarantee of normal tourist activities ${ }^{[1]}$. With the development of tourism industry, tourism safety has become increasingly prominent, which has also become a hot issue in the academic and industrial circles ${ }^{[2]}$. Majority of the researches on tourism safety focus on countries ${ }^{[3-4]}$, cities ${ }^{[5-7]}$, scenic spots ${ }^{[8,9]}$, etc. And there are also some other researches that don't have specific purposes but focus on which aspect tourists care about of tourism safety based on their previous travelling experiences or potential willingness to travel ${ }^{[10,11]}$. Perception of tourism safety is the subjective cognition and evaluation of tourists on the safety of tourist destinations ${ }^{[4]}$. Previous researches have shown that there are differences in the perception of tourism safety among tourists of different age ${ }^{[5]}$ and gender ${ }^{[12]}$. Moreover, the differences also lie in where tourists come from ${ }^{[3,5]}$, their purposes for travels ${ }^{[5]}$, the number of visits ${ }^{[8]}$, travel experience ${ }^{[13]}$ and so on. However, there is a lack of researches on domestic source of tourists on the provincial scale, especially the comparison of potential tourists.

Xinjiang is vast, which is the largest province-level administrative region in China. It boasts rich tourism resources and is an important tourist destination in the northwest of China. With the development of the Belt and Road, the tourism industry in Xinjiang is embracing a good opportunity. However, there're also many challenges. For example, there have been many tourism safety incidents in Xinjiang which had negative effects on the tourism development in Xinjiang. Tourists from CircumBohai Sea, Yangtze River Delta and Pearl River Delta are the main new source of tourists to Xinjiang. Therefore, Beijing, Shanghai, Guangzhou and Chengdu are selected as the representative cities in each region, and the potential tourists from the four cities will be investigated. In this paper, exploratory factor analysis is used to study the dimensions of tourists' perception of safety. Furthermore, and one-way ANOVA is used to compare the differences among potential tourists from different places.

\section{Materials and Methods}

\subsection{Data Sources}

The data in this paper are obtained from questionnaires. The questionnaire consists of two parts: the first part is about tourists' perception of safety, containing 28 items. And each item is scored by the Likert five-point scale. The higher the score is, the higher the scale of tourists' perception of safety will be. The second part is about the demographic characteristics of the respondents, including gender, age, educational background, occupation, monthly income, etc. In August and December 2019, field surveys were conducted in local places, such as libraries, malls, parks in Beijing, Shanghai, Guangzhou and Chengdu. After the preliminary screening, a total of 903 valid questionnaires for potential tourists were obtained.

Among the samples, $51.16 \%$ of them are from males and $48.50 \%$ from females, which means the proportion of males and females is basically the same. $92.80 \%$ of the respondents are young and middle-aged, from 18 years old to $45.90 .92 \%$ of the respondents are from college or above. The proportion of each income level is relatively balanced, as the respondents come from all walks of life, so the questionnaire is representative. The samples from Beijing,

\footnotetext{
278125866@qq.com

* Corresponding author: bjfwu@snnu.com.cn
} 
Shanghai, Guangzhou and Chengdu account for $26.69 \%$, $26.80 \%, 24.92 \%$ and $21.26 \%$ respectively.

\subsection{Research Methods}

This paper uses SPSS 21.0 to conduct the exploratory factor analysis of the items of tourists' perception of safety. First of all, the reliability of the scale is tested by Cronbach's $\alpha$; Second, the feasibility of factor analysis is tested by KMO and Bartlett spherical test; Third, the common factors are extracted by principal component extraction and maximum variance rotation. Each common factor is named according to what it explains to determine the dimensions of tourists' perception of safety. One-way ANOVA is used to test whether there are significant differences in the dimensions and items of tourists' perception of safety among the four groups which are Beijing, Shanghai, Guangzhou and Chengdu.

\section{Results \& Discussion}

\subsection{Dimensions of Tourists' Perception of Safety}

Cronbach's $\alpha$ Test is performed on the scale of the 28 items of tourists' perception of safety, and the result is 0.967 . It means that the questionnaire has good consistency and it can be trusted. Then KMO sampling measure and Bartlett spherical test are performed on the 28 items. The test result of the KMO test is 0.945 , which is larger than 0.800 . Meanwhile, the result of the Bartlett spherical test is 19112.321, which is significant at the level of 0.000 . It means the 28 items are closely related and they' re suitable for factor analysis. After preliminary analysis, 28 variables are reduced to 5 main factors whose cumulative contribution rate is $70.311 \%$. Among them, the maximum load the item, "unfriendly locals", is less than 0.5 . So the item is excluded to improve the result of factor analysis.

\subsection{Comparison of Regional Differences in Tourists' Perception of Safety}

One-way ANOVA is used to analyze the dimensions and factors of the perception of safety of tourists from the four regions. We want to know whether there are significant differences among the four groups, and the results are shown in Table 1.

Table1. Results of One-way ANOVA Analysis of Tourists' Perception of Safety

\begin{tabular}{|c|c|c|c|c|c|c|c|}
\hline Factor & Beijing & Shanghai & Guangzhou & Chengdu & $\mathrm{F}$ & Sig & Conclusion \\
\hline Elements of Tourist Activities & 3.343 & 3.268 & 3.069 & 3.110 & 5.194 & 0.001 & Significant \\
\hline Swarm and Jostlement & 3.544 & 3.471 & 3.212 & 3.342 & 4.456 & 0.004 & Significant \\
\hline Tourist Facilities & 3.328 & 3.250 & 3.115 & 3.197 & 1.595 & 0.189 & Insignificant \\
\hline Traffic Accident & 3.320 & 3.242 & 3.031 & 3.104 & 3.332 & 0.019 & Significant \\
\hline Fire and Explosion & 3.282 & 3.232 & 3.057 & 3.026 & 2.817 & 0.038 & Significant \\
\hline Infectious Disease & 3.208 & 3.180 & 2.938 & 2.891 & 5.061 & 0.002 & Significant \\
\hline Food Safety & 3.342 & 3.205 & 3.004 & 3.052 & 4.800 & 0.003 & Significant \\
\hline Accommodation Environment & 3.096 & 2.975 & 2.821 & 2.850 & 3.177 & 0.023 & Significant \\
\hline Tourist Conflict & 3.611 & 3.579 & 3.357 & 3.399 & 3.256 & 0.021 & Significant \\
\hline Tourist Services & 2.771 & 2.806 & 2.521 & 2.617 & 4.820 & 0.002 & Significant \\
\hline Defrauding Tourists & 2.707 & 2.768 & 2.405 & 2.578 & 5.206 & 0.001 & Significant \\
\hline Shopping Fraud & 2.754 & 2.806 & 2.467 & 2.542 & 5.102 & 0.002 & Significant \\
\hline Tourists' Complaints & 2.738 & 2.847 & 2.551 & 2.620 & 3.442 & 0.016 & Significant \\
\hline Scenic Spot Services & 2.979 & 3.050 & 2.718 & 2.819 & 4.920 & 0.002 & Significant \\
\hline Taxi Service & 2.779 & 2.756 & 2.524 & 2.635 & 2.966 & 0.031 & Significant \\
\hline Rescue Ability & 2.675 & 2.610 & 2.463 & 2.510 & 1.641 & 0.178 & Insignificant \\
\hline Public Security & 2.655 & 2.463 & 2.423 & 2.364 & 4.076 & 0.007 & Significant \\
\hline Going Out At 11:00 & 2.477 & 2.279 & 2.374 & 2.150 & 3.505 & 0.015 & Significant \\
\hline Violent and Terrorist Events & 2.425 & 2.299 & 2.235 & 2.161 & 2.252 & 0.081 & Insignificant \\
\hline Theft and Robbery & 2.692 & 2.517 & 2.405 & 2.367 & 3.768 & 0.011 & Significant \\
\hline Police Presence & 2.622 & 2.423 & 2.460 & 2.440 & 1.582 & 0.192 & Insignificant \\
\hline Pornography, Gambling and Drug & 3.058 & 2.796 & 2.640 & 2.700 & 5.976 & 0.000 & Significant \\
\hline Natural Disaster & 3.514 & 3.453 & 3.057 & 3.292 & 13.810 & 0.000 & Significant \\
\hline Snow Disaster & 3.768 & 3.781 & 3.336 & 3.740 & 9.283 & 0.000 & Significant \\
\hline Mountain Landslide & 3.558 & 3.535 & 3.199 & 3.352 & 5.597 & 0.001 & Significant \\
\hline Earthquake & 4.062 & 4.037 & 3.681 & 4.047 & 8.260 & 0.000 & Significant \\
\hline Hot Weather & 3.133 & 3.174 & 2.664 & 2.586 & 15.297 & 0.000 & Significant \\
\hline Adaptation to Climate & 3.054 & 2.740 & 2.396 & 2.734 & 12.050 & 0.000 & Significant \\
\hline Culture Conflict & 2.734 & 2.770 & 2.505 & 2.548 & 4.077 & 0.007 & Significant \\
\hline Offending Customs & 2.638 & 2.608 & 2.352 & 2.400 & 3.951 & 0.008 & Significant \\
\hline Religious Taboos & 2.558 & 2.558 & 2.313 & 2.337 & 3.520 & 0.015 & Significant \\
\hline Language Barrier & 3.008 & 3.145 & 2.850 & 2.907 & 2.918 & 0.033 & Significant \\
\hline
\end{tabular}




\subsubsection{Tourists' Perception of Safety of Tourist Activities}

According to Table 1, it shows that there are significant differences in the perception of the elements of tourist activities among the tourists from different geographical groups. It shows that as for the perception of safety of the elements of tourist activities, that of tourists from Beijing and Shanghai are much higher than that of tourists from Chengdu and Guangzhou. Seen from some specific safety factors, the mean values of "tourist facilities" are close, which means there is no significant difference among the results of one-way ANOVA. However, there are significant differences among the seven factors, "swarm and jostlement", "traffic accident", "fire and explosion", "infectious disease", "food safety", "accommodation environment" and "tourist conflict". Similarly, the values of Beijing and Shanghai are remarkably higher than those of Chengdu and Guangzhou.

\subsubsection{Tourists' Perception of Safety of Tourist Services}

Table 1 shows that there are significant differences in the perception of safety of tourist services among the tourists from different geographical groups. We know, as for the perception of safety of tourist services, the values of Shanghai and Beijing are significantly higher than those of Chengdu and Guangzhou. Seen from some specific safety factors, the mean values of "rescue ability" are close, which means there is no significant difference among the results of one-way ANOVA. However, there are significant differences among the five factors, "defrauding tourists", "shopping fraud", "tourists' complaints", "scenic spot services", "taxi service". Similarly, the values of Beijing and Shanghai are remarkably higher than those of Chengdu and Guangzhou.

\subsubsection{Tourists' Perception of Safety of Public Security}

Table 1 shows that there are significant differences in the perception of safety of public security among the tourists from different geographical groups. We know, as for the perception of safety of public security, the values of Beijing and Shanghai are significantly higher than those of Guangzhou and Chengdu. Seen from some specific safety factors, the mean values of the two factors, "violent and terrorist events" and "police presence", of different geographical groups are close, which means there is no significant difference among the results of one-way ANOVA. However, there are significant differences among the other three factors, "going out at 11:00", "theft and robbery" and "pornography, gambling and drug abuse". Among them, the values of "theft and robbery" and "pornography, gambling and drug abuse" of Beijing and Shanghai are significantly higher than those of Guangzhou and Chengdu. However, as for the value of "going out at 11:00", the values of Beijing and Guangzhou are higher than those of Shanghai and Chengdu.

\subsubsection{Tourists' Perception of Safety of Natural Disaster}

Table 1 shows that there are significant differences in the perception of safety of natural disaster among the tourists from different geographical groups. We know, as for the perception of safety of natural disaster, the values of Beijing and Shanghai are significantly higher than those of Chengdu and Guangzhou. Seen from some specific safety factors, there are significant differences among the five factors, "snow disaster", "mountain landslide", "earthquake", "hot weather", "adaptation to climate". As for the values of "snow disaster" and "mountain landslide", the mean values of Beijing, Shanghai and Chengdu are close, all apparently higher than that of Guangzhou. In terms of "hot weather", the values of Shanghai and Beijing are close, both apparently higher than those of Guangzhou and Chengdu. The value of "adaptation to climate" of Beijing is significantly higher than those of Shanghai and Guangzhou while Chengdu witnesses the lowest value. The values of "earthquake" of Beijing, Guangzhou and Shanghai are close, all apparently higher than that of Chengdu.

\subsubsection{Tourists' Perception of Safety of Cultural Conflict}

Table 1 shows that there are significant differences in the perception of safety of cultural conflict among different geographical groups. We know, as for the perception of safety of cultural conflict, the values of Shanghai and Beijing are significantly higher than those of Chengdu and Guangzhou. Seen from some specific safety factors, there are significant differences among the three factors, "offending customs", "religious taboos" and "language barrier". And the values of these factors of Shanghai and Beijing are significantly higher than those of Chengdu and Guangzhou.

\subsection{Comparison of Dimension Structure of Tourists' Perception of Safety}

After analyzing the values of the safety perception of tourists from Beijing, Shanghai, Guangzhou and Chengdu, we use the factor analysis method to compare the dimension structure of the safety perception of the tourists from the four cities. In the end, 28, 25, 28 and 26 factors of tourists' perception of safety are kept for Beijing, Shanghai, Guangzhou and Chengdu respectively. (As shown in Fig. 1)

As shown in Fig. 1, five common factors are extracted from the factors of the safety perception of the potential tourists from Beijing, and they are named as "elements of tourist activities", "tourist services", "public security", "natural disaster and climatic environment" and "cultural conflict". Moreover, the cumulative contribution rate of total variance of the five common factors is $72.544 \%$, which means the five common factors can replace the original 28 factors of tourists' perception of safety. Six common factors are extracted from the factors of the safety perception of the potential tourists from Shanghai, 
and they are named as "elements of tourist activities", "public hygiene", "tourist services", "public security", "natural disaster and climatic environment" and "cultural conflict". The cumulative contribution rate of total variance of the six common factors is $73.065 \%$, which means the six common factors can replace the original 28 factors of tourists' perception of safety. Five common factors are extracted from the factors of the safety perception of the potential tourists from Guangzhou, and they are named as "elements of tourist activities", "tourist services", "public security", "natural disaster and climatic environment" and "cultural conflict". The cumulative
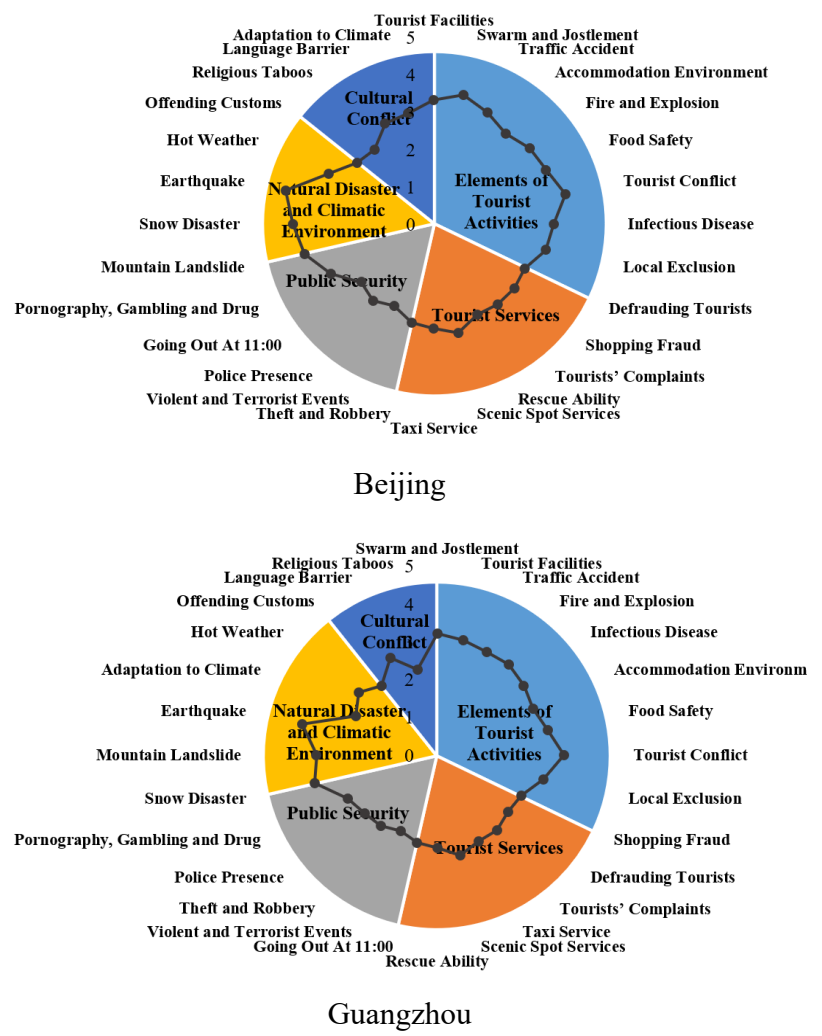

contribution rate of total variance of the five common factors is $71.043 \%$, which means the six common factors can replace the original 28 factors of tourists' perception of safety. Six common factors are extracted from the factors of the safety perception of the potential tourists from Chengdu, and they are named as "elements of tourist activities", "climatic environment", "tourist services", "natural disaster" and "cultural conflict". The cumulative contribution rate of total variance of the six common factors is $74.292 \%$, which means the six common factors can replace the original 28 factors of tourists' perception of safety.
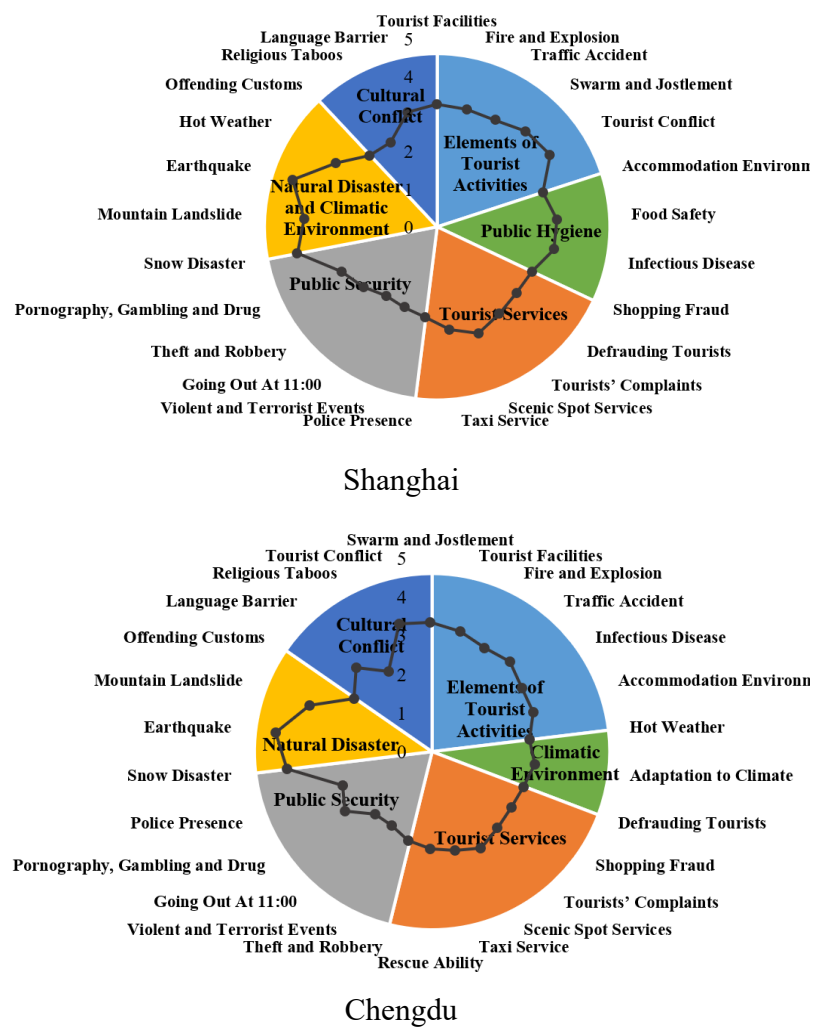

Fig 1. Dimension Structure of Factors of Tourists' Perception of Safety

From the dimension structure of tourists' perception of safety, there're four same dimensions of tourists' perception of safety among those of Beijing, Shanghai, Guangzhou and Chengdu, which are "elements of tourist activities", "tourist services", "public security" and "cultural conflict". As is analyzed above, there are regional differences in these four dimensions, but they are still regarded as the basic dimensions to measure tourists' perception of safety. Besides, Beijing, Shanghai and Guangzhou also share one more same dimension, which is "natural disaster and climatic environment". However, the factors in the same dimension of Beijing, Shanghai and Guangzhou belong to the two dimensions of Chengdu which are "natural disaster" and "climatic environment". Maybe it's because those who live in Chengdu suffered a severe earthquake and they have a different understanding of natural disasters. In addition, a new dimension is extracted among those of Shanghai, which is "public hygiene". And there're three factors in this dimension, which are "accommodation environment", "food safety" and "infectious disease", but they belong to "elements of tourist activities" in the other three groups. It means potential tourists from Shanghai don't treat public hygiene as a normal element of tourist activities but a single new dimension.

\section{Conclusions}

The results show that there are no significant differences in the four factors of potential tourists' perception of safety of Xinjiang, which are "tourist facilities", "rescue ability", "violent and terrorist events", and "police presence", while significant differences lie in the other 23 factors. On the whole, as for the values of factors of tourists' perception of safety to Xinjiang, those of Beijing and Shanghai are generally higher than those of Chengdu and Guangzhou. Besides, the values of that of Beijing and Shanghai are close while the values of that of Chengdu and Guangzhou are relatively close. There are similarities and differences in the dimension structure of the factors of safety perception of Xinjiang among the potential tourists 
from the four cities. What they share in common is the four dimensions, which are "elements of tourist activities", "tourist services", "public security" and "cultural conflict". Besides, Beijing, Shanghai and Guangzhou also share one more same dimension, which is "natural disaster and climatic environment". In addition, a new dimension is extracted among those of Shanghai, which is "public hygiene". The four dimensions, "elements of tourist activities", "tourist services", "public security" and "cultural conflict", are regarded as the basic dimensions to measure tourists' perception of safety, while "natural disaster and climatic environment" is also an important dimension.

The research results of this paper only represent the subjective impression and evaluation of tourist safety in Xinjiang of the potential tourists, which can't represent the real situation of tourist safety in Xinjiang. Perception of safety of a person relies on their subjective judgments made according to the information in their minds, the experiences, and their own personalities, so it can't fully reflect the objective and real state of safety of a place.

\section{Acknowledgments}

This work is supported by the National Natural Science Foundation of China (No. 41671135) and the Fundamental Research Funds for the Central Universities (No. 2017TS113).

\section{References}

1. Zhang, J.F., Zheng X.M. (2001) Tourism Safety Research. J. Journal of Huaqiao University (Humanities and Social Sciences Edition), 01:15-22.

2. Wan H.L., Zhang M., Song H.L. (2018) Shi W.J. Review on Domestic Tourist Safety Studies from 1990 to 2016. J. Economic Geography, 38:213-219.

3. Barker, M., Page, S.J., Meyer, D. (2003) Urban Visitor Perceptions of Safety during a Special Event. J. Journal of Travel Research, 41: 355-361.

4. He, Y.M., Zou Y.G., Mo, Y.Q. (2019) Study on Safety Perception of Chinese Tourists to Malaysia -- Based on Web Text Analysis. J. World Geographic Studies, 28: 200-210.

5. George, R. (2003) Tourist's Perceptions of Safety and Security While Visiting Cape Town. Tourism Management, 24: 575-585.

6. Zou, Y.G., Zheng, X.M. (2012) Empirical Study on the Influencing Factors of Tourists' Perception of safety to Destinations: a Case Study of Quanzhou, Fujian. J. Journal of Tourism, 27:49-57.

7. Lin, W.L., Lai, S.Z., Zou, Y.G. (2017) Mechanism of Influence of Safe Environment on Tourists' Safety Behavior in Coastal Resorts: Empirical Data from Sanya and Xiamen. J. Journal of Tourism, 32: 104116.

8. George, R. (2010) Visitor perceptions of crime-safety and attitudes towards risk: The case of Table Mountain National Park, Cape Town. J. Tourism
Management, 31: 806-815.

9. Zou, Y.G., Zheng, X.M. (2011) Safety Evaluation Model and Empirical Study of Tourist Attractions. J. Chinese Journal of Safety Sciences, 21:156-162.

10. Wang, J.J., Zheng, X.M. (2015) Empirical Study on the Impact of Tourists' Safety Perception to the Travel Intention of Urban Residents: A Case Study of Urban Residents in Representative Cities in China. J. Journal of Leshan Normal University, 30: 61-68.

11. Qiao, X.Y. (2018) Empirical Study on the influencing factors of female tourists' safety perception: a Case Study of Tianjin Female Tourists. J. Business and Management, 12:139-143.

12. Wu, B.H., Wang, X., Li, M.M. (2001) Study on Perceived Evaluation of Tourist Safety of Chinese College Students. J. Journal of Guilin Vocational School, 03: 62-68.

13. Sonmez, S. F., Graefe, A. R. (1998). Influence of terrorism risk on foreign tourism decisions. J. Annals of Tourism Research, 25: 112-144. 